\title{
Expression of eosinophil $\beta$ chain-signaling cytokines receptors, outer-membrane integrins, and type 2 inflammation biomarkers in severe non-allergic eosinophilic asthma
}

Virginija Kalinauskaite-Zukauske ${ }^{1 *+}$ (D), Andrius Januskevicius ${ }^{2+}$, leva Janulaityte ${ }^{2}$, Skaidrius Miliauskas ${ }^{1}$ and Kestutis Malakauskas ${ }^{1,2}$

\begin{abstract}
Background: Severe non-allergic eosinophilic asthma (SNEA) is a rare asthma phenotype associated with severe clinical course, frequent exacerbations, and resistance to therapy, including high steroid doses. The key feature is type 2 inflammation with predominant airway eosinophilia. Eosinophil maturation, activation, survivability, and recruitment are mainly induced by interleukin (IL)-3, IL-5 and granulocyte-macrophage colony-stimulating factor (GM-CSF) through their receptors on eosinophil surface and related with integrins activation states. The aim of the study was to estimate the expression of eosinophil $\beta$ chain-signaling cytokines receptors, outer-membrane integrins, and serum-derived type 2 inflammation biomarkers in SNEA.
\end{abstract}

Methods: We examined 8 stable SNEA patients with high inhaled steroid doses, 12 steroid-free patients with non-severe allergic asthma (AA), 12 healthy subjects (HS). Blood eosinophils were isolated using Ficol gradient centrifugation and magnetic separation. Eosinophils were lysed, and mRNA was isolated. Gene expressions of IL-5Ra, IL-3Ra, GM-CSFRa, and $a 4 \beta 1, a M \beta 2$ integrins were analyzed using quantitative real-time reverse transcription polymerase chain reaction. Type 2 inflammation activity was evaluated measuring exhaled nitric oxide concentration (FeNO) collected with the electrochemical sensing device. Serum IL-5, IL-3, GM-CSF, periostin, chemokine ligand (CCL) 17 and eotaxin concentrations were assessed by enzyme-linked immunosorbent assay.

Results: Eosinophils from SNEA patients demonstrated significantly increased gene expression of IL-3Ra, LL-5Ra and GM-CSFRa as well as $a 4, \beta 1$ and aM integrin subunits compared with the AA group. The highest IL-5 serum concentration was in the SNEA group; it significantly differed compared with AA and HS. GM-CSF serum levels were similar in the SNEA and AA groups and were significantly lower in the HS group. No differences in serum IL-3 concentration were found among all groups. Furthermore, serum levels of eotaxin, CCL17 and FeNO, but not periostin, differed in all groups, with the highest levels in SNEA patients.

Conclusions: Eosinophil demonstrated higher expression of IL-3, IL-5, GM-CSF a-chain receptors and a4, $\beta 1$, aM integrins subunits in SNEA compared with the AA group. Additionally, SNEA patients had increased serum levels of IL-5, eotaxin and CCL-17.

Trial registration: ClinicalTrials.gov Identifier NCT03388359.

Keywords: Severe non-allergic eosinophilic asthma, Eosinophil, IL-5, IL-3, GM-CSF, Integrins, Eotaxin, CCL17

\footnotetext{
* Correspondence: virginija.kalinauskaite@lsmuni.It

${ }^{\dagger}$ Virginija Kalinauskaite-Zukauske and Andrius Januskevicius contributed equally to this work.

${ }^{1}$ Department of Pulmonology, Lithuanian University of Health Sciences,

Kaunas, Lithuania

Full list of author information is available at the end of the article
}

(c) The Author(s). 2019 Open Access This article is distributed under the terms of the Creative Commons Attribution 4.0 International License (http://creativecommons.org/licenses/by/4.0/), which permits unrestricted use, distribution, and reproduction in any medium, provided you give appropriate credit to the original author(s) and the source, provide a link to the Creative Commons license, and indicate if changes were made. The Creative Commons Public Domain Dedication waiver (http://creativecommons.org/publicdomain/zero/1.0/) applies to the data made available in this article, unless otherwise stated. 


\section{Background}

Asthma is a common lung disorder that usually lasts the sufferer's lifetime. Despite the wide range of treatment options, in some cases, patients encounter a significant loss of quality of life, reduced work productivity, greater mortality risk, and higher health care resource use and costs $[1,2]$. Severe asthma affects less than $10 \%$ of all asthma cases, but the treatment costs are high [3], disease severity is a major factor for clinical and economic burden [4]. This rare phenotype has sub-classifications driven by distinct pathophysiological processes. One of the severe asthma subtypes is a severe non-allergic eosinophilic asthma (SNEA), which is characterized by severe clinical course, frequent exacerbations of the disease, resistance to treatment including high doses of systemic glucocorticoids, and poorer clinical outcome $[5,6]$ as well as a good response to biologicals such as treatment with anti-IL-5 antibodies. The basis of this disease is eosinophilic airway inflammation, which plays a pivotal role in the pathogenesis of both allergic and non-allergic asthma, but the paths through which the genesis is initiated varies. In allergic asthma cases, Th2 cells mainly release prototype cytokines such as interleukin (IL) 4, IL-5 and IL-13, thereby stimulating type 2 immunity, which has high antibody titers and eosinophilia. Non-allergic asthmatics have increased numbers of type 2 innate lymphoid cells (ILC2s), that upon stimulation with the epithelial cytokines produce Th2-associated cytokines, including high amounts of IL-5, which is important for eosinophilic maturation and migration [7, 8]. This might explain severe eosinophilic inflammation in the absence of classical Th2-mediated allergy [9]. However, the eosinophilic properties themselves may be responsible for some eosinophilic inflammation features.

Eosinophils are circulating granulocytes that are produced via granulopoiesis in the bone marrow. IL-3, IL-5, and granulocyte-monocyte colony-stimulating factor (GM-CSF) are cytokines that are particularly important in regulating eosinophil development [10]. These three cytokines, also called eosinophilopoietins, are responsible for eosinophil maturation, activation, survivability, and apoptosis [10]. To recruit circulating eosinophils from the blood into the lungs, they need to be activated $[11,12]$. For the most part, it depends on cytokines IL-3, IL-5, GM-CSF, as well as their receptors [11, 13]. The receptors for IL-3, IL-5 and GM-CSF each have unique $\alpha$-chains but share a common $\beta$-chain. The $\beta$-chain is essential for signal transduction and explains the overlapping activities of these cytokines. The overexpression of these cytokines or their receptors can lead to excessive or aberrant initiation of signaling, which results in pathological conditions [14]. A marked increase in eosinophil count in the tissues and blood is observed in SNEA cases, but data are lacking on whether this is due to the quantitative values of these three major cytokines or the change in expression of the receptor on the eosinophil.

Another important part of the inflammatory process in the asthma pathogenesis is direct eosinophil adhesion to a target cell, which is relevant for eosinophil activation and functions. Integrins are cellular receptors that contain an $\alpha$ and a $\beta$ subunits that regulate extravasation of eosinophils from the bronchial circulation to the airway wall and airspace. Such movement into the asthmatic lung depends on integrins on circulating eosinophils. Eosinophils tether in flow and roll on bronchial endothelial cells, integrins on rolling eosinophils become further activated because of exposure to cytokines, eosinophils arrest firmly to adhesive ligands on the activated endothelium, and eosinophils transmigrate to the airway in response to chemoattractants $[15,16] . \alpha 4 \beta 1$ and $\alpha \mathrm{M} \beta 2$ are likely the two most important integrins that mediate eosinophil adhesion and movement [16]. There is evidence that a change in the integrin expression can attenuate eosinophil-induced airway smooth muscle remodeling in asthma [17].

Currently-used type 2 inflammation biomarkers are peripheral blood eosinophils, sputum eosinophil count, exhaled nitric oxide concentration (FeNO), immunoglobulin $\mathrm{E}$ (IgE), serum periostin concentration, but some of them have limitations [18]. Sputum eosinophil count is calculated only in large centres, tissue-specific, time-consuming test. FeNO is cheap, not specific, loses specificity in smokers. No clear association has been identified between IgE or allergy as a biomarker of treatment responses or clinical outcome. Periostin measurement is poor available, confounded by growth in childhood, pregnancy, and dental disease. There is an increasing need for useful type 2 inflammation biomarkers, controlled the recruitment of activated eosinophils from the bloodstream into tissues, like CCL11 (eotaxin), CCL17, with predictive and prognostic value for the progression of the disease in SNEA patients and their link with clinical treatments.

We hypothesized that differences exist in eosinophil biological properties during SNEA compared with nonsevere AA. Therefore, it was important to investigate factors that reflect eosinophil activity like specific cytokines and their receptors as well as integrin expression. The purpose of our study was to evaluate the expression of the main eosinophilopoietins IL-3, IL-5 and GM-CSF receptors and integrin subunits $\alpha 4, \alpha M, \beta 1, \beta 2$ at the surface of eosinophils. Therefore, we investigated serum levels of type 2 inflammation biomarkers as eotaxin, periostin, and CCL17 chemokines.

\section{Methods}

\section{Study population}

The research protocol was approved by the Regional Biomedical Research Ethics Committee of the Lithuanian University of Health Sciences (BE-2-13). The study was 
registered in the U.S. National Institutes of Health trial registry ClinicalTrials.gov with identifier NCT03388359.

The study included patients with SNEA, those who were free of steroid non-severe AA, and healthy subjects (HS), who comprised the control group. The participants were men and women between the ages of 18 and 50 years who signed written informed consent. The patients were recruited from the Department of Pulmonology, Hospital of the Lithuanian University of Health Sciences.

Inclusion criteria for the SNEA group were: asthma diagnosis for at least 12 months; non-allergic phenotype, approved clinically and with negative skin prick tests; peripheral eosinophil count $\geq 0.3 \times 10^{9} / 1$ during the screening visit or $\geq 0.15 \times 10^{9} / 1$ if with documented eosinophil count $\geq 0.3 \times 10^{9} / 1$ in the 12 -month period before the screening; no other reasons that could lead to poor control of asthma symptoms; documented at least 12-month treatment of high doses of inhaled corticosteroids combined with long-acting beta-agonist \pm long-acting antimuscarinic agent \pm episodic use of oral corticosteroids prior to inclusion in the study; in the 12 months before the screening visit $\geq 2$ exacerbations of asthma that required treatment with systemic glucocorticoids.

The non-severe AA group comprised individuals with newly-established and untreated non-severe AA, approved with symptoms and medical history more than 1 year, positive skin prick test to clinically relevant allergen(s), and positive bronchial challenge with methacholine or bronchodilator reversibility test.

Healthy subjects should have been without allergic and other chronic respiratory diseases.

Exclusion criteria included asthma exacerbation $\leq 1$ month prior to the study, clinically significant permanent allergy symptoms, active airway infection 1 month prior the study, use of oral steroids $\leq 1$ month prior to study, and treatment with targeted (biological) therapy (e.g. omalizumab, mepolizumab, benralizumab).

All participants were neither current nor former smokers.

\section{Pulmonary function testing}

The lung function was evaluated for all study subjects by measuring baseline forced expiratory volume in $1 \mathrm{~s}\left(\mathrm{FEV}_{1}\right)$, forced vital capacity (FVC), and $\mathrm{FEV}_{1} / \mathrm{FVC}$ ratio using a Ganshorn spirometer (Ganshorn Medizin Electronic, Germany) and compared with the standardized values according to investigated individual sex, age and height. Each of these values was measured three times and recorded only the highest of three reproducible measurements.

\section{Testing airway responsiveness}

The airway responsiveness test was performed for AA patients and healthy individuals. Testing was performed using inhaled methacholine via a pressure dosimeter (ProvoX, Ganshorn Medizin Electronic, Germany). Aerolized methacholine was inhaled at 2-min intervals starting with a $10,1 \mu \mathrm{g}$ methacholine dose and increasing it by steps until was achieved a $20 \%$ decrease in $\mathrm{FEV}_{1}$ from the baseline value either consumed the total cumulative methacholine dose of $1310 \mu \mathrm{g}$. Methacholine induced bronchoconstriction was expressed in percentage decrease of $\mathrm{FEV}_{1}$ from the baseline value. $\mathrm{PD}_{20}$ (methacholine dose causing a $\geq 20 \%$ fall in $\mathrm{FEV}_{1}$ ) was measured from the logarithmic dose-response curve by linear interpolation of two adjacent data points.

\section{Bronchial reversibility test}

$\mathrm{FEV}_{1}$, FVC were registered before and $20 \mathrm{~min}$ after salbutamol administration (200 mcg by MDI) using a Ganshorn spirometer (Ganshorn Medizin Electronic, Germany). A positive response to a bronchodilator generally is defined as an increase of $\geq 12 \%$ and $\geq 200 \mathrm{ml}$ as an absolute value compared with baseline in either $\mathrm{FEV}_{1}$ or FVC. A bronchial reversibility test was performed for one subject in the AA group because testing airway responsiveness was not possible due to observed bronchial obstruction at the screening visit.

\section{FeNO measurement}

All study subjects underwent fractional exhaled nitric oxide (FeNO) analysis with an on-line method using a single breath exhalation and an electrochemical assay (NIOX $\mathrm{VERO}^{\circ}$, Circassia, UK), according to ATS-ERS guidelines. Patients inspired eNO-free air via a mouthpiece immediately followed by full exhalation at a constant rate $(50 \mathrm{~mL} / \mathrm{s})$ for at least $10 \mathrm{~s}$. The mean of three readings at the end of the expiration (plateau phase) was taken as the representative value for each measurement. Values of $25 \mathrm{ppb}$ or higher were considered elevated according to ATS-ERS criteria.

\section{Skin prick test}

Skin prick tests were used to measure study individuals sensitivity for suspected and/or the most common allergy-causing substances (D. pteronyssinus, D. farinae, cat and dog dander, five mixed grass pollen, birch pollen, and mugwort allergen) by using standardizes allergen extracts (Stallergenes S.A., France). Negative control was performed with diluent (saline) and positive control with histamine hydrochloride $(10 \mathrm{mg} / \mathrm{mL})$. Results of the test were evaluated $15 \mathrm{~min}$ after application. The skin prick test was considered appropriate when the mean wheal diameter was $\geq 3 \mathrm{~mm}$.

\section{Eosinophils isolation}

Sterile BD Vacutainer tubes supplemented with EDTA was used for a collection of peripheral blood. Peripheral 
blood granulocytes isolated by high-density Ficoll (GE Healthcare, Finland) centrifugation and hypotonic lysis of erythrocytes. The whole blood was added on Ficoll layer and centrifuged at $600 \mathrm{~g}$ force for $30 \mathrm{~min}$ at room temperature. Lower layer collected and washed with sterile $\mathrm{H}_{2} \mathrm{O}$ and 2xPBS until no red erythrocytes colour were left.

Negative selection magnetic eosinophils isolation (Miltenyi Biotec, USA) were used to seperate eosinophils from granulocytes mixture according to the method shown previously [19]. Eosinophils were separated in $97 \%$ purity and at least $95 \%$ viability. Purity was confirmed with May-Grunwald-Giemsa staining and light microscopy; viability with automatic cell counter ADAM (Witec AG, Switzerland) based on propidium iodide staining.

\section{RNA isolation and real-time PCR}

We isolated whole cells RNA by using the commercial miRNeasy mini kit (Qiagen, Valencia, CA) based on the manufacturer's provided recommendations. RNA samples with high protein contamination (A260/A280 ratio below 1.8 or above 2.0) or with lower RNA concentration than $20 \mathrm{ul} / \mathrm{ml}$ were excluded from experiments. Real-time PCR was carried out by using a Power SYBR ${ }^{\circ}$ Green RNA-to- $\mathrm{C}_{\mathrm{T}}{ }^{\mathrm{Tu}}$ 1-Step kit (Applied Biosystems, Foster City, CA) with Fast Real-Time PCR 7500 system in following conditions: reverse transcription - at $48^{\circ} \mathrm{C}$ (30 min); activation of AmpliTaq Gold ${ }^{\circ}$ DNA polymerase - at $95^{\circ} \mathrm{C}(10 \mathrm{~min})$; denaturation - at $95^{\circ} \mathrm{C}(0.25 \mathrm{~min})$; annealing - at $50-60{ }^{\circ} \mathrm{C}(0.5 \mathrm{~min})$ depending by primers; extension - at $72{ }^{\circ} \mathrm{C}(0.5 \mathrm{~min})$. Denaturation, annealing and extension were repeating for 40 cycles. Received qPCR data were analyzed by the comparative cycle threshold method. Data were normalized to $18 \mathrm{~S}$ ribosomal RNA endogenous gene. Primers used to analyze gene expression are shown in Table 1.

\section{Detection of protein level in investigating individuals blood serum samples}

Protein (IL-5, IL-3, GM-CSF, periostin, chemokine ligand (CCL) 17 and eotaxin) levels in blood serum samples were measured by the enzyme-linked immunosorbent assay (ELISA) according to the instructions provided by manufacturers. ELISA kits used for experiments: IL-5 (Invitrogen, Carlsbad, California, US) LLD - 1.5 pg/ml; IL-3 (Invitrogen, Carlsbad, California, US) LLD- $1 \mathrm{pg} / \mathrm{ml}$; Eotaxin (Invitrogen, Carlsbad, California, US) LLD-2.2 pg/ml; Periostin (Thermo Scientific, Waltham, Massachusetts, US) LLD 80 pg $/ \mathrm{ml}$; CCL-17 (Thermo Scientific, Waltham, Massachusetts, US) LLD-5 pg/ml; GM-CSF (Affymetrix, Santa Clara, California, US) LLD-2.9 pg/ml. 100 ul of serum samples were used for experiments. Blood was collected into BD Vacutainer ${ }^{\circ}$ Blood Collection Tubes and allowed to clot for
$30 \mathrm{~min}$. After that tubes were centrifuged at $1000 \times g, 10$ $\min , 4^{\circ} \mathrm{C}$ to remove the clot. The resulting supernatant is designated serum. Serum immediately collected and poured into $1 \mathrm{ml}$ cryogenic tubes and frozen in $-80^{\circ} \mathrm{C}$ for protein levels analysis. ELISA measurements were performed after the sufficient amount of samples was collected. The results were expressed as protein concentration per $1 \mathrm{ml}$ of serum.

\section{Statistical analysis}

Data statistics were performed by using the GraphPad Prism 6 (ver. 6.05, 2014; GraphPad Software Inc., San Diego, CA). Normally distributed gene expression data represented as the mean and standard error of the mean (SEM), protein concentration data as median [range]. Data statistics between independent groups were determined using the Mann-Whitney $U$-test, for dependent groups - the Wilcoxon matched-pairs signed-rank test. One sample t-test was used for statistical analysis with reference to theoretical mean. Results considered statistically significant when $p<0.05$.

\section{Results}

Characteristics of the study population

We examined 32 nonsmoking adults (11 men and 21 women): 8 SNEA patients, 12 steroid-free non-severe AA patients, and 12 healthy controls. The SNEA group was distinguished not only by the increased blood eosinophil count, but also by age, lung function, and FeNO concentration (Table 2). The atopy component had only AA group patients. The IgE level was highest in the AA group and significantly differed from that in the SNEA group $(p<0.05)$.

\section{Expression of $\beta$-chain cytokines receptors by eosinophils}

We investigated three main cytokines - IL-5, IL-3, and GM-CSF $\alpha$-chain receptors gene expression, which are responsible for eosinophil activation, maturation, and survivability in eosinophils from SNEA, AA, and healthy individuals. We found that in SNEA group IL-3R $\alpha$ and IL-5R $\alpha$ gene expressions were significantly increased by $2.5 \pm 0.3$-fold and $5.3 \pm 0.7$-fold, respectively $(p<0.05)$, compared with healthy controls, whereas expression of GM-CSFR $\alpha$ did not differ $(1.1 \pm 0.2$-fold, $p=0.56)$. Comparing the AA group with healthy control subjects, we estimated that IL-3R $\alpha$ gene expression increased by $1.5 \pm 0.2$-fold $(p<0.05)$, but IL-5R $\alpha$ and GM-CSFR $\alpha$ were significantly decreased by $3.1 \pm 1$.2-fold and $2.4 \pm$ 0.4 -fold, respectively ( $\mathrm{p}<0.05$; Fig. 1 ). Furthermore, we found significant differences in gene expression between the SNEA and AA groups. Eosinophils in SNEA patients significantly increased the gene expressions of IL-3R $\alpha$, IL- $5 \mathrm{R} \alpha$ and GM-CSFR $\alpha$ by $1.7 \pm 0.2$-fold; $8.0 \pm 1.0$-fold and $2.1 \pm 0.3$-fold respectively $(\mathrm{p}<0.05)$. 
Table 1 Primers of cytokine receptors and integrin subunits used in the qPCR analysis

\begin{tabular}{lll}
\hline Gene & Forward primer & Reverse primer \\
\hline I8S (reference) & 5'-CGC CGC TAG AGG TGA AAT TC-3' & 5'-TTG GCA AAT GCT TTC GCT C-3' \\
IL-5Ra & 5'-AAT GAT CTT TाT CTA GGT AGA-3' & 5'-CCT CTG GAG CTT GAG ATA-3' \\
IL-3Ra & 5'-TTA AGC AGG CAC CTC TGT CC-3' & 5'-CTG AGC CTT TGC TाT CAT CC-3' \\
GM-CSFRa & 5'-GCA TTC CTC CTG ATC CCA GA-3' & 5-CCT GGA GTC AAA CCT CAC ATT G-3' \\
aM & 5'- CAG ACA GGA AGT AGC AGC TCC T-3' & 5'- CTG GTC ATG TTG ATG AAG GTG CT-3' \\
$\beta_{1}$ & 5'-GTG TGG CCC AAG ACA GTT CT-3' \\
$a_{4}$ & 5'- GCT TCT CAG ATC TGC TCG TG-3' & 5'-GGT TAC CCC ACC CTC TGA CT-3' \\
$\beta_{2}$ & 5'-AAC GTA TGC GAG TGC CAT TC-3' & 5'- GTC ACT TCC AAC GAG GTT TG-3' \\
\hline
\end{tabular}

\section{IL-3, IL-5, and GM-CSF serum levels}

IL-3 levels in serum did not differ among the SNEA, AA, and HS groups: it was 7.8 [7.3-8.1] pg/ml, 7.7 [6.9-8.6] $\mathrm{pg} / \mathrm{ml}$, and 7.9 [6.9-10.0] pg/ml, respectively (Fig. 2a). IL5 levels were significantly higher in the SNEA group (14.5 [12.6-18.8] pg/ml) compared with the AA and HS groups $(9.3[1.7-17.03] \mathrm{pg} / \mathrm{ml}$ and $3.2[0.2-11.5] \mathrm{pg} / \mathrm{ml}$, respectively; Fig. 2b). No difference existed in GM-CSF levels in serum between the SNEA and AA groups (64.2 [56.1-81.2] $\mathrm{pg} / \mathrm{ml}$ and 59.1 [44.2-112.8] $\mathrm{pg} / \mathrm{ml}$, respectively, $p>0.05$ ); however, these levels were higher than in the HS group (45.91 [41.7-63.4] pg/ml; Fig. 2c).

\section{Eosinophil integrin expression}

We investigated gene expression of two main outermembrane integrins, $\alpha_{4} \beta_{1}$ and $\alpha M \beta_{2}$, by blood eosinophils, isolated from SNEA, AA, and healthy individuals. Both the SNEA and AA groups had significantly more mRNA of $\alpha 4$ (3.5 \pm 0.7 -fold and $1.8 \pm 0.2$-fold, $p<0.05$ ), $\alpha \mathrm{M} \quad(10.2 \pm 4.9$-fold and $2.7 \pm 1.3$-fold, $\mathrm{p}<0.05), \quad \beta 2$ $(2.5 \pm 0.7$-fold and $1.8 \pm 0.3$-fold, $p<0.05)$ and only
SNEA group has increased $\beta 1$ expression by $4.2 \pm 2.0$ fold compared with mRNA levels in healthy eosinophils $(p<0.05)$.

We revealed that eosinophils from the SNEA group had significantly more expressed $\alpha 4, \beta 1$ and $\alpha M$ integrins subunits than those from the AA group (respectively by $2.1 \pm 0.4$-fold, $3.1 \pm 1.5$-fold, and $3.8 \pm 1.8$-fold, $\mathrm{p}<0.05$; Fig. 3).

\section{Type 2 inflammation biomarkers}

We investigated the levels of periostin, eotaxin and CCL17 serum levels in collected samples and observed the highest periostin levels in SNEA and AA groups, at 66.5 [54.2-131.5] ng/ml and 86.3 [63.3-161.7] $\mathrm{ng} / \mathrm{ml}$, respectively, without significant difference between these groups $(p>0.05)$. However, these levels were significantly higher than those in the HS group (40.0 [30.345.0] $\mathrm{ng} / \mathrm{ml}, \mathrm{p}<0.05$; Fig. 4a). The eotaxin level in the SNEA group was significantly higher than that in the AA and HS groups (224.2 [183.7-275.1] pg/ml, 164.7 [116.1-184.7] $\mathrm{pg} / \mathrm{ml}$, and $89.2[47.1-168.5] \mathrm{pg} / \mathrm{ml}$, respectively; Fig. 4b). Differences in CCL17 concentration

Table 2 Demographic and clinical characteristics of the study population

\begin{tabular}{|c|c|c|c|}
\hline & SNEA group patients & AA group patients & Healthy subjects \\
\hline Number, n & 8 & 12 & 12 \\
\hline Sex, M/F & $1 / 7$ & $7 / 5$ & $3 / 9$ \\
\hline Age, years & $52.0^{* \#} \pm 4.2$ & $26.0 \pm 2.4$ & $29.0 \pm 2.2$ \\
\hline $\mathrm{BMl}, \mathrm{kg} / \mathrm{m}^{2}$ & $25.5 \pm 1.9$ & $25.1 \pm 1.8$ & $22.5 \pm 1.5$ \\
\hline $\mathrm{FEV}_{1}, \mathrm{I}$ & $1.5 \pm 0.2^{* \#}$ & $4.0 \pm 0.2$ & $3.9 \pm 0.2$ \\
\hline $\mathrm{FEV}_{1}, \%$ of predicted & $56.6 \pm 7.2^{* \#}$ & $94.6 \pm 3.8$ & $103.8 \pm 2.7$ \\
\hline $\mathrm{PD}_{20}$, mean (range), $\mathrm{mg}(\mathrm{n})^{\gamma}$ & ND & $0.11 \pm 0.02$ & NR \\
\hline Blood eosinophil count, $\times 10^{9} / \mathrm{I}$ & $0.71 \pm 0.17^{* \#}$ & $0.33 \pm 0.06^{\#}$ & $0.20 \pm 0.02$ \\
\hline FeNO, ppb & $59.3 \pm 10.1^{* \#}$ & $57.6 \pm 5.5^{\#}$ & $14.3 \pm 1.4$ \\
\hline $\lg \mathrm{E}, \mathrm{IU} / \mathrm{ml}$ & $128.3 \pm 30.2^{* \#}$ & $174.3 \pm 26.5^{\#}$ & $33.0 \pm 7.1$ \\
\hline
\end{tabular}

$A A$ Allergic asthma, SNEA Severe non-allergic eosinophilic asthma, $F$ Female, $M$ Male, $F E V_{1}$ Forced expiratory volume in $1 \mathrm{~s}, P D_{20}$ The provocation dose of methacholine causing a $20 \%$ decrease in $\mathrm{FEV}_{1}$, FeNO Fractional exhaled nitric oxide, IgE Immunoglobulin E, ND Not done, NR Not responded Data presented as the mean \pm standard error of the mean

vairway responsiveness was tested for 10 AA subjects; 1 subject had positive bronchial reversibility test ${ }^{*} p<0.01$ comparing with AA group

$\# p<0.01$ comparing with HS group 


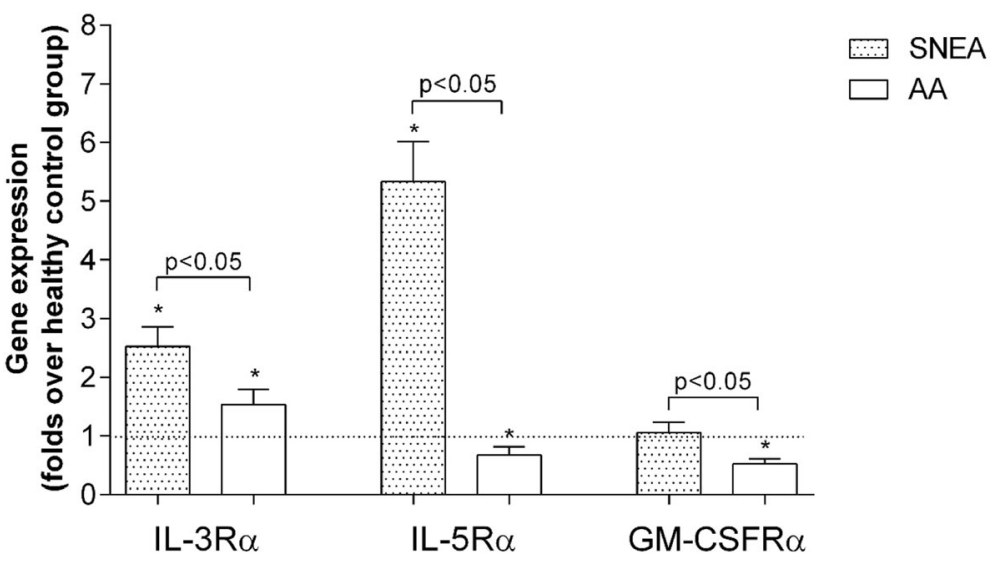

Fig. 1 Genes expression of IL-3, IL-5 and GM-CSF receptors in eosinophils. Results presented as mean \pm SEM. Severe non-allergic eosinophilic asthma (SNEA) group $n=8$, non-severe allergic asthma (AA) group $n=12$, healthy control group $n=12 .{ }^{*} p<0.05$ comparing with healthy control group. Statistical analysis - Mann-Whitney U-test for analysis between SNEA and AA; One sample t-test for analysis against HS group

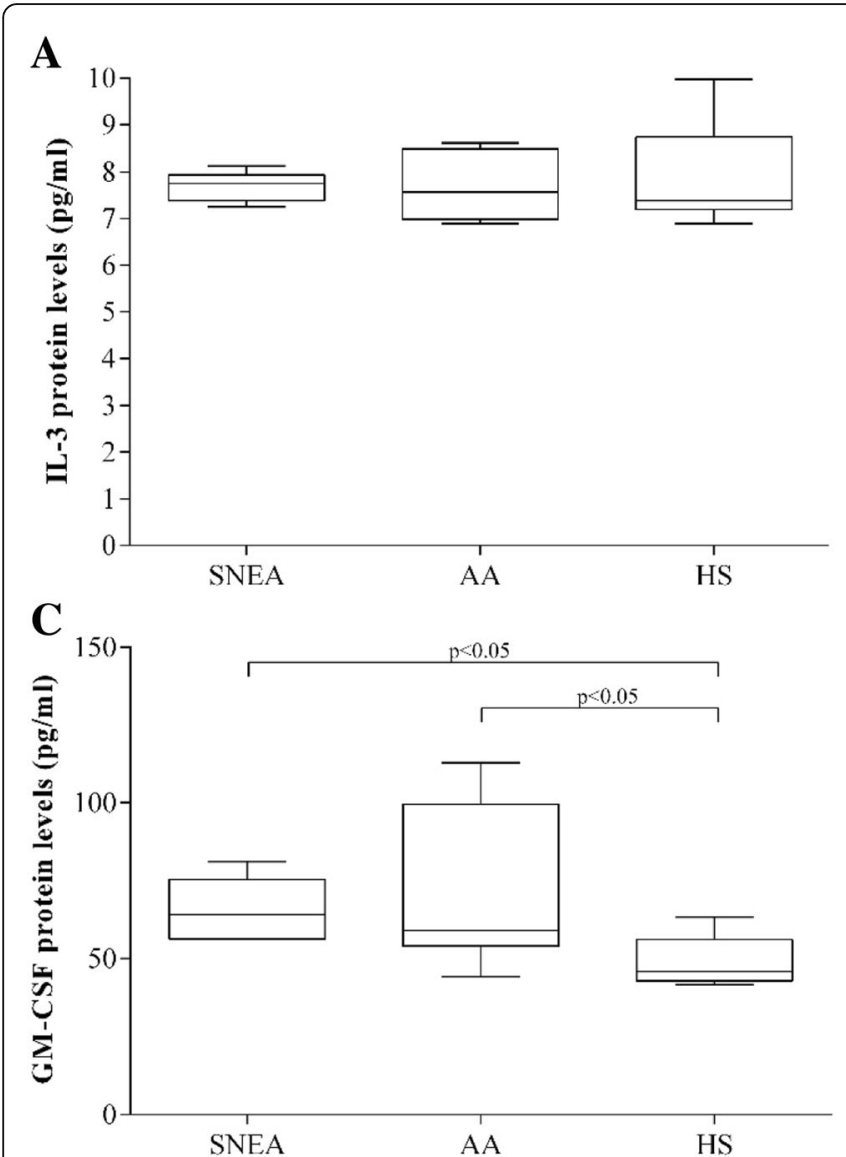

Fig. 2 Serum levels of eosinophil maturation and activation cytokines. (a) IL-3 protein level. (b) IL-5 protein level. (c) GM-CSF protein level. Results presented as median (range). Severe non-allergic eosinophilic asthma (SNEA) group $n=5$, non-severe allergic asthma (AA) group $n=11$, healthy control group $n=10$. Statistical analysis - Mann-Whitney U-test 


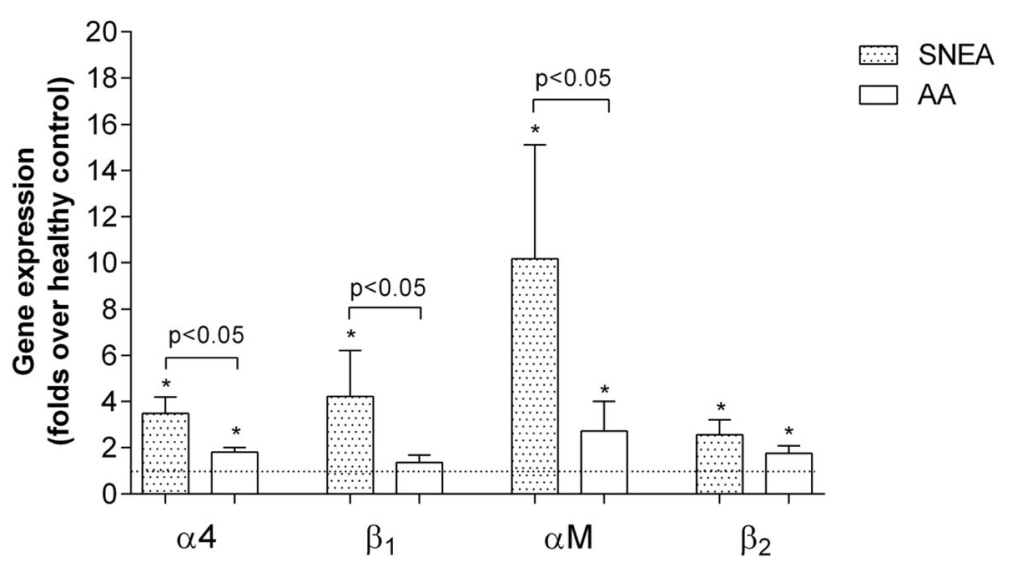

Fig. 3 Gene expression of eosinophil integrins. Results presented as mean \pm SEM. Severe non-allergic eosinophilic asthma (SNEA) group $n=8$, non-severe allergic asthma (AA) group $n=12$, healthy control group $n=12 .{ }^{*} p<0.05$ comparing with healthy control group. Statistical analysis Mann-Whitney U-test for analysis between SNEA and AA; One sample t-test for analysis against HS group
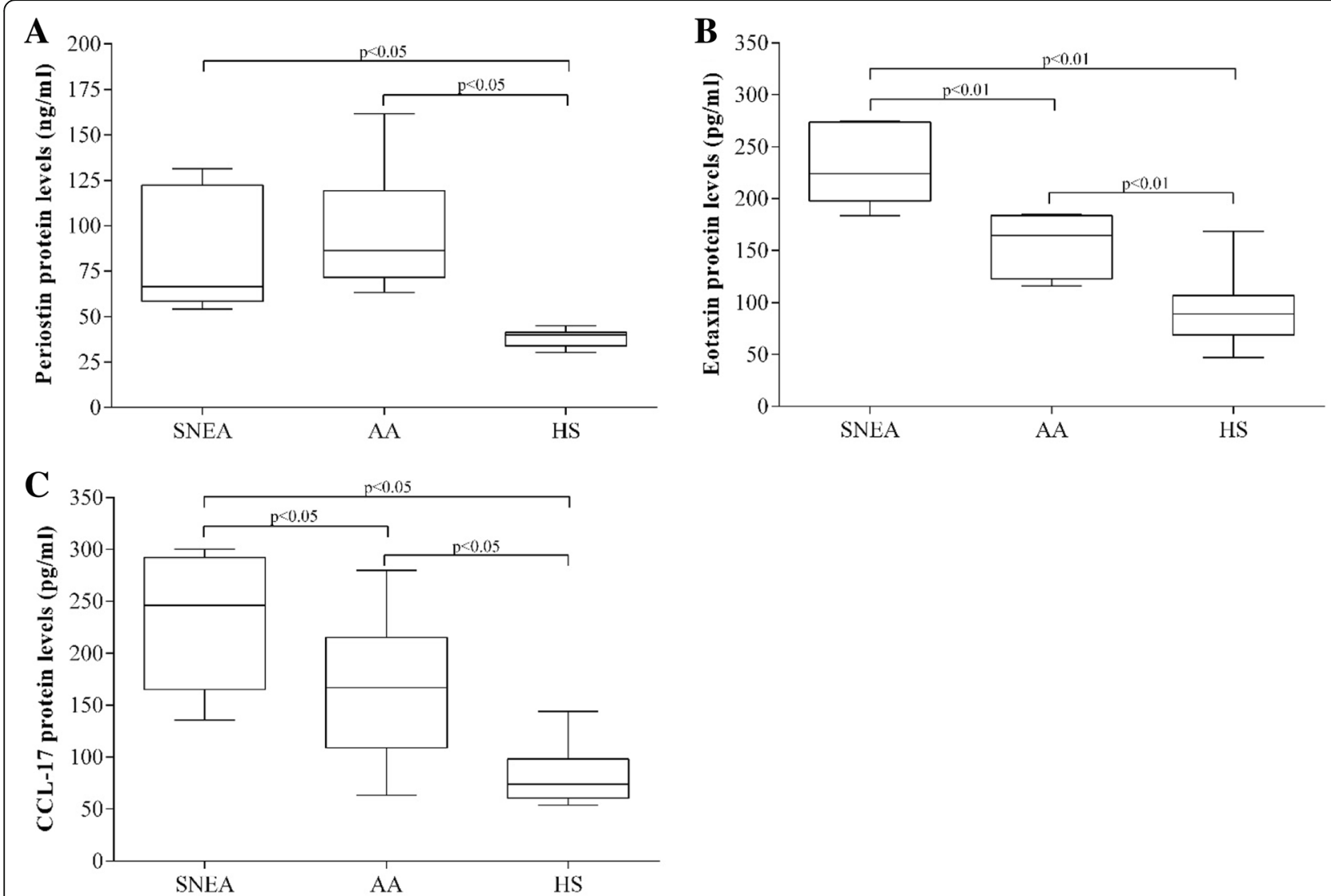

Fig. 4 Serum levels of potential biomarkers for asthma severity. (a) Periostin protein level. (b) Eotaxin protein level. (c) CCL17 protein level. Results presented as median [range]. Severe non-allergic eosinophilic asthma (SNEA) $n=5$, non-severe allergic asthma (AA) group $n=11$, healthy control group $n=10$. Statistical analysis - Mann-Whitney U-test 
in serum samples were similar to those in eotaxin levels - the highest CCL17 concentration was in the SNEA group (246.1 [135.6-300.4] pg/ml), medium in the AA group $(167.0$ [63.2-279.9] $\mathrm{pg} / \mathrm{ml})$ and lowest in the HS group (73.7 [53.7-144.2] pg/ml; Fig. 4c).

\section{Discussion}

Several clinical parameters, like eosinophil count, decreased lung function, uncontrolled course and frequent disease exacerbations, and resistance to glucocorticoid treatment, help clinicians to differentiate severe and non-severe courses of asthma. However, in many cases, these clinical data could overlap or be insufficiently expressed, which limits clinicians' ability to appoint appropriate medication. Therefore, new biological differences between asthma phenotypes should be revealed. In this study, we aimed to find which disease pathogenesis-associated biological aspects of eosinophils in SNEA patients could help to explain more severe disease course. We found that IL-3, IL-5, GM-CSF receptors, and $\alpha 4, \beta 1$ and $\alpha \mathrm{M}$ integrin subunit expression by eosinophils is increased in SNEA patients compared with non-severe AA patients. Moreover, IL-5R $\alpha$ changes function from downregulation in AA patients to upregulation in SNEA patients. Furthermore, we identified higher eotaxin and CCL-17 serum levels, which in combination with validated eosinophilic inflammatory biomarkers could help to distinguish severe eosinophilic asthma, and predict the disease course, treatment effectiveness, and outcome.

Currently, the eosinophil count is the best-identified marker to determine eosinophilic asthma severity [20]. However, the number of eosinophils in patients with different types of asthma can overlap significantly and cause confusion among clinicians about appropriate treatment. Increased eosinophil count in peripheral blood is important, but not the only factor that contributes to disease pathogenesis because only pre-activated cells could significantly contribute to disease pathophysiological features. Eosinophil infiltration from blood to asthmatic airway depends on primed blood eosinophils, which leads to their arrest on activated endothelium, extravasation into the airway wall, and migration through airway tissues to the airway lumen. Eosinophil pre-activation is associated with maturation and activation mediators like $\beta$ receptor-signaling cytokines IL-3, IL-5, and GM-CSF in the blood [21]. These eosinophilopoietins are responsible not only for eosinophil maturation in bone marrow but they also contribute to the regulation of eosinophils surface proteins, including integrins, intracellular adhesion molecule-1, cytokines receptors, L-selectin, CD-13 and others [22]. In our study, we measured mRNA levels of these cytokine $\alpha$ receptors in eosinophils in different investigating groups.
The relationships between gene expression of these receptors and its ligands - IL-3, IL-5 and GM-CSF is not completely clear, confirming that signal transmission through receptor depends not only on ligand concentration but also on the number of receptors. IL-3 serum levels did not differ between investigating groups, but IL-3R $\alpha$ gene expression in the SNEA group was significantly increased, which may show increased IL-3 signaling. GM-CSF serum level was similar in SNEA and AA patients but significantly increased compared with HS. However, the gene expression of GM-CSFR $\alpha$ in SNEA patients did not differ compared with healthy controls but significantly decreased in the AA group. This suggests that though GM-CSF serum levels were similar in SNEA and AA patients, its altered receptor expression shows increased GM-CSF signaling in SNEA patients. Intriguing results were observed regarding IL-5 concentration and its receptor expression. The highest serum concentration of IL-5 was in the SNEA group; this significantly differed from those in the AA and HS groups. IL-5R $\alpha$ also increased dramatically in SNEA patients, while it significantly decreased in the AA group. This reveals a flip from downregulation to upregulation, which highlights the important role of IL-5 signaling in SNEA patients. However, recent therapeutic approaches targeting IL-5 alone have not completely ablated tissue accumulation of eosinophils and have had limited effects on disease progression, which suggests important roles for IL-3 and GM-CSF. $\beta$-chain cytokines change their roles at a different stage of disease development; moreover, expression of their receptors is regulated by different signaling pathways. Our result partly agrees with the works of Gregory et al., and Uchiyama et al., who investigated how IL-3, IL-5, and GM-CSF cross-regulate expression of these cytokine $\alpha$ receptors in healthy eosinophils $[23,24]$. These teams revealed that IL-5R $\alpha$ was downregulated and IL-3R $\alpha$ was upregulated by all $\beta$-chain cytokines, while GM-CSFR $\alpha$ was downregulated by GM-CSF, but was not affected by IL-3 or IL-5. However, the situation in asthma could be different due to complex pathogenesis interrupted by chronic inflammation conditions. Our results showed that GM-CSF could not downregulate its receptor expression in SNEA patients. More interestingly, according to Gregory et al., and Uchiyama et al., IL-5R $\alpha$ expression in SNEA patients decreased dramatically. However, we found that IL-5 serum levels increased over 7-fold, but there was an important shift in IL-5R $\alpha$, with a visible significant increase in its mRNA levels by over 5 -fold compared with healthy controls and 8-fold compared with AA. There is no clear explanation about these significant changes. As blood eosinophils count in SNEA patients is significantly increased compared with AA and HS, signaling through IL-5R $\alpha$ might take an important part in enhanced eosinophilic inflammation and their survival. Increased mRNA levels of IL-5R $\alpha$ could be associated with the soluble form of this receptor 
that can be generated by differential splicing of mRNA transcripts [25] or by cleavage of surface receptors [26]. Wilson et al. demonstrated that increased serum IL-5 levels and blood eosinophil count, as observed in our SNEA patients group, elevates soluble IL-5R $\alpha$ [27]. Moreover, receptors expression is primarily controlled by specific transcription factors, which role in the regulation of eosinophils IL-5R $\alpha$ transcription is almost unknown in asthma. Therefore, this altered process can lead to increased mRNA levels of IL-5R $\alpha$ and different AA and SNEA pathogenesis. This may have implications with respect to the use of novel therapeutic agents targeting IL- 5 and its receptor in patients with eosinophilia. However, IL-5 is recognized as an effective biomarker for other diseases in which eosinophilia is detected [28, 29]; therefore, its role as a biomarker for asthma severity is not yet defined.

Increased expression of eosinophil integrins is an important factor for more stable and enhanced adhesion mediating cell activation by interacting with counter-receptors on other cells or an extracellular matrix $[15,30]$. Eosinophil expresses seven-transmembrane heterodimeric integrins, but $\alpha 4 \beta 1$ and $\alpha M \beta 2$ receive the most important in asthma [15, 31]. Previously, enhanced expression of these integrins was identified in newly-diagnosed AA patients with the significant blocking effect of small tetrapeptide Arg-Gly-Asp-Ser (RGDS) [17]. Moreover, higher numbers of $\alpha 4 \beta 1$ and $\alpha M \beta 2$ integrins in an activated state are related with better eosinophil arrest on endothelium cells that express elevated amount of vascular cell adhesion molecules-1 (VCAM-1) - the ligand for $\alpha 4 \beta 1$ [32] and intercellular adhesion molecule-1 (ICAM-1) for $\alpha \mathrm{M} \beta 2$ [33] thus contributing to increased eosinophilic airway inflammation. Although evidence exists about eosinophil integrin expression during $\mathrm{AA}$, there are none about the expression of these integrins during SNEA. In our study, we found that expression of $\alpha \mathrm{M}, \alpha 4$, and $\beta 1$ integrin subunits in eosinophils from SNEA patients significantly differ from AA patients. This suggests increased adhesive properties of these integrins required for enhanced infiltration into the lungs. Studies with integrin-deficient mice revealed that $\alpha 4$ and $\beta 2$ integrins enhance eosinophil recruitment to the airways [34]. However, our study did not show significant $\beta 2$ expression differences between SNEA and AA groups, which suggests that an amount of $\beta 2$ subunit in eosinophils is sufficient and that only increased expression of the $\alpha M$ subunit is required for enhanced eosinophil activation through $\alpha M \beta 2$ integrin, as was found in the SNEA group (Fig. 1). Additionally, Johansson et al. discovered that blood eosinophils stimulated with IL-5, IL-3, or GM-CSF specifically adhere and migrate to periostin via activated aM $\beta 2$ [35]. We confirmed that serum levels of periostin increased in SNEA and AA patients compared with healthy controls, as well as by IL-3, IL-5, and GM-CSF depending signaling in SNEA. However, because in SNEA only IL-5 levels and the expression of its receptors significantly increases, this may be the main trigger that activates $\mathrm{aM} \beta 2$ integrins in eosinophils, leading to their enhanced recruitment into the lungs. Periostin, as a ligand for $\mathrm{aM} \beta 2$, may act as an activator for eosinophils, but more important is their role modulating eosinophil transmigration, chemoattraction, and adhesion [36]. All these features could be activated in an autocrine manner because eosinophil is a predominant periostin producing cells in the blood [37].

Some overlap in asthma phenotypes can lead to an overlap in eligibility for the different biological therapies. Therefore, more specific biological markers should be identified which, together with well-known clinical properties, could help to separate SNEA in early-stage investigations. Blood eosinophil count is a good marker to identify eosinophilic asthma phenotype, together with sputum eosinophils count, which is the best-identified marker for airway eosinophilia. The number of eosinophils in sputum can be used as a marker of disease severity, with strong associations among airway eosinophilia, the severity of disease symptoms, and worsened lung function [38]. Unfortunately, sputum eosinophil count and their activity tend to be influenced by the current, mostly corticosteroid therapy and are not consistent, and airway eosinophilia could prevail in many asthma phenotypes. Asthma has a multicomponent pathology, and sputum eosinophil count alone does not disclose variability in asthmatics [39]. Currently, sputum eosinophil measurements are used only in places with limited clinical equipment because of its complexity and practical difficulties.

Many studies revealed the periostin as a significant marker to identify tissue eosinophilia, but our research data suggest that periostin alone is not suitable to identify asthma severity because of similar possible corticosteroid-affected periostin levels in SNEA and steroid-free AA patient groups. Moreover, periostin, as a marker, according to its expression mechanisms, is linked to antiIL-13 [40] or anti-IgE treatment [40], but not with IL-5 associated biological therapies. FeNO is weakly affected by corticosteroid treatment and could be a more effective biomarker for asthma severity [41]. We tested our subjects and found significant differences in FeNO concentration among SNEA or AA and healthy control study groups. Increased FeNO level in the exhaled gas of asthma patients is linked to T-helper type 2 (Th2)mediated inflammation [42]. FeNO strongly correlates with a sputum eosinophilia and lung functions and could help to identify eosinophil recruitment to asthmatic lungs. However, our data indicate that though differences in FeNO level exist between SNEA and AA 
groups, the disparity is insufficient to distinguish these two asthma phenotypes. This finding is in agreement with several reports that indicated the discordance between treatment response or adjustment and FeNO levels, especially after anti-IL-5 treatment [43-45].

In our study, eotaxin and CCL-17 protein act as the most selective markers because their levels in blood serum samples vary depending by asthma severity. One important study was made, indicating eotaxin as a potential diagnostic marker for asthma. Data analysis of thirty different studies revealed that eotaxin sputum level is a potential biomarker for asthma severity, but eotaxin serum level is also associated with lung function, sputum eosinophil count, eosinophil cationic proteins level, and FeNO [46]. Unfortunately, no anti-eotaxin approaches have been made so far. As Th2-mediated inflammation is associated with specific chemokines expression, like CCL-17 protein, by lung tissue cells for specific Th2 cell recruitment and activation, these chemokines in serum could act as specific biomarkers for disease severity. Significant correlations between CCL-17 and the severity of various diseases were published [47-49], highlighting its usage in allergic conditions, but no data exist on non-allergic asthma with predominant eosinophilia. We think that the release of eosinophilopoietins by CCL-17 activated Th2 cells leading to eosinophil maturation in SNEA patients reveals the role of CCL-17 as a potential biomarker. Recently was demonstrated that CCL17 and eotaxin are regulated by IL-4/IL-13 pathway and using anti-interleukin-4 receptor $\alpha$ monoclonal antibodies significantly reduce serum levels of eotaxin and CCL-17 [50]. Different concentrations of eotaxin and CCL-17 between SNEA and AA patients can be explained by Th2 cells, or ILC2 generated IL-4 and IL-13 cytokine levels, leading to altered activity of IL-4/IL-13 signaling pathway and its role in SNEA and AA pathogenesis.

There are some limitations to our study. First, a small number of patients with SNEA were investigated. However, this was sufficient to find significant differences between our study groups. Moreover, ICS treatment could also affect gene expression and protein levels, but to date, there is only evidence about the inhibitory effect of ICS that indicates that our received differences should be even higher. Also, almost all SNEA patients were older age women; consequently, it is necessary to assess the possible effects of ageing and sex on study objectives. To date, it has not been determined whether eosinophils differ by gender. Adhesion of eosinophils and chemotaxis upon eotaxin stimulation do not differ significantly between younger and older subjects [51]. However, no data show how eosinophil receptor expression changes with ageing. It has been noted that eosinophil degranulation in response to IL-5 stimulation is significantly decreased in older patients [51], but data were obtained not in a disease context. Furthermore, eosinophil receptor and integrin expression were possible to investigate only in mRNA levels that in rare cases, do not correlate with protein levels due to several parameters [52].

\section{Conclusion}

We found that eosinophils in SNEA patients differ from those in AA because of increased gene expression of IL-3, IL-5, GM-CSFR receptors $\alpha$-chains and $\alpha 4, \beta 1, \alpha M$ integrins subunits, in conjunction with enhanced serum levels of IL-5. Moreover, increased serum levels of eotaxin and CCL-17 may become potential SNEA biomarkers.

\section{Abbreviations \\ AA: Allergic asthma; ASM: Airway smooth muscle; CCL17: Chemokine ligand 17; DNA: Deoxyribonucleic acid; ELISA: Enzyme-linked immunosorbent assay; FeNO: Exhaled nitric oxide concentration; GM-CSF: Granulocyte-macrophage colony-stimulating factor; HS: Healthy subjects; IgE: Immunoglobulin E; IL- 3: Interleukin 3; IL-4: interleukin 4; IL-5: Interleukin 5; IL-13: Interleukin 13; ILC2s: Type 2 innate lymphoid cells; PMN: Polymorphonuclear leukocytes; RNA: Ribonucleic acid; RT-qPCR: Real-time reverse transcription polymerase chain reaction; SEM: Standard error of the mean; SNEA: Severe non-allergic eosinophilic asthma; Th2: T helper 2 lymphocytes}

\section{Acknowledgements}

We are grateful to Rokas Stonkus for his help with laboratory experiments of all participants.

KM and AJ are members of COST Action CA15214: An Integrative Action for Multidisciplinary Studies on Cellular Structural Networks.

\section{Authors' contributions}

Conceived and designed the experiments: KM, SM, AJ, VKZ, IJ. Performed the experiments: AJ, VKZ, IJ. Analyzed the experimental data: KM, VKZ, AJ, IJ. Take care of patients, analyzed clinical data: VKZ. Contributed reagents/materials/ analysis tools: IJ, VKZ, AJ. Revised the manuscript for intellectual content: KM, SM, AJ, VKZ, IJ. All authors have read and approved the final manuscript.

\section{Funding}

This research received no external funding.

\section{Availability of data and materials}

The datasets used and/or analysed during the current study are available from the corresponding author on reasonable request.

\section{Ethics approval and consent to participate}

The study protocol was approved by the Regional Biomedical Research Ethics Committee of the Lithuanian University of Health Sciences (BE-2-13). Each participant provided informed written consent.

\section{Consent for publication}

The consents have been obtained to publish from the participant to report individual patient data.

\section{Competing interests}

The authors declare that they have no competing interests.

\section{Author details}

'Department of Pulmonology, Lithuanian University of Health Sciences, Kaunas, Lithuania. 'Laboratory of Pulmonology, Department of Pulmonology, Lithuanian University of Health Sciences, Kaunas, Lithuania. 
Received: 8 November 2018 Accepted: 23 July 2019 Published online: 22 August 2019

\section{References}

1. Custovic A, Johnston S, Pavord I, Gaga M, Fabbri L, Bel E, et al. EAACl position statement on asthma exacerbations and severe asthma. Allergy. 2013;68(12):1520-31.

2. Calhoun WJ, Haselkorn T, Mink DR, Miller DP, Dorenbaum A, Zeiger RS Clinical burden and predictors of asthma exacerbations in patients on guideline-based steps 4-6 asthma therapy in the TENOR cohort. J Allergy Clin Immunol Pract. 2014:2(2):193-200.

3. Ortega HG, Liu MC, Pavord ID, Brusselle GG, FitzGerald JM, Chetta A, et al. Mepolizumab treatment in patients with severe eosinophilic asthma. N Engl J Med. 2014;371(13):1198-207.

4. Chastek B, Korrer S, Nagar SP, Albers F, Yancey S, Ortega H, et al. Economic burden of illness among patients with severe asthma in a managed care setting. J Manag Care Spec Pharm. 2016;22(7):848-61.

5. Carr TF, Berdnikovs S, Simon H-U, Bochner BS, Rosenwasser L. Eosinophilic bioactivities in severe asthma. World Allergy Organ J. 2016;9(1):21.

6. Al-Muhsen S, Johnson JR, Hamid Q. Remodeling in asthma. J Allergy Clin Immunol. 2011;128(3):451-62.

7. Spits H, Artis D, Colonna M, Diefenbach A, Di Santo JP, Eberl G, et al. Innate lymphoid cells - a proposal for uniform nomenclature. Nat Rev Immunol. 2013;13(2):145

8. Walker JA, Barlow JL, McKenzie AN. Innate lymphoid cells-how did we miss them? Nat Rev Immunol. 2013;13(2):75.

9. Brusselle GG, Maes T, Bracke KR. Eosinophils in the spotlight: eosinophilic airway inflammation in nonallergic asthma. Nat Med. 2013;19(8):977.

10. Park YM, Bochner BS. Eosinophil survival and apoptosis in health and disease. Allergy Asthma Immunol Res. 2010;2(2):87-101.

11. Koenderman L. Priming: a critical step in the control of eosinophil activation. In: Lee JJ, Rosenberg HF, editors. Eosinophils in Health and Disease. Amsterdam: Elsevier; 2013. p. 170-9. Available at: https://books. google.lt/books?id=ADg8kX9|EdYC\&pg=PA170\&dq=Priming:+a+critical+ step+in+the+control+of+eosinophil+activation\&hl=|t\&sa $=X \& v e d=$ OahUKEwjRt5WojtfjAhWOAxAIHReTDOYQ6AEIKDAA\#v=onepage $\& q=$ Priming\%3A\%20a\%20critical\%20step\%20in\%20the\%20control\%20of\%2 0eosinophil\%20activation\&f=false

12. Johansson MW, Mosher DF. Integrin activation states and eosinophil recruitment in asthma. Front Pharmacol. 2013;4:33.

13. Chung KF. Asthma phenotyping: a necessity for improved therapeutic precision and new targeted therapies. J Intern Med. 2016;279(2):192-204.

14. Broughton SE, Dhagat U, Hercus TR, Nero TL, Grimbaldeston MA, Bonder CS, et al. The GM-CSF/IL-3/IL-5 cytokine receptor family: from ligand recognition to initiation of signaling. Immunol Rev. 2012;250(1):277-302.

15. Barthel SR, Johansson MW, McNamee DM, Mosher DF. Roles of integrin activation in eosinophil function and the eosinophilic inflammation of asthma. J Leukoc Biol. 2008;83(1):1-12.

16. Calderwood D. Talin controls integrin activation. Biochem Soc Trans. 2004 Jun;32(Pt3):434-7.

17. Januskevicius A, Gosens R, Sakalauskas R, Vaitkiene S, Janulaityte I, Halayko $\mathrm{AJ}$, et al. Suppression of eosinophil integrins prevents remodeling of airway smooth muscle in asthma. Front Physiol. 2017;7:680.

18. Pavord ID, Beasley R, Agusti A, Anderson GP, Bel E, Brusselle G, et al. After asthma: redefining airways diseases. Lancet. 2018;391(10118):350-400.

19. Januskevicius A, Vaitkiene S, Gosens R, Janulaityte I, Hoppenot D, Sakalauskas R, Malakauskas K. Eosinophils enhance WNT-5a and TGF- $\beta_{1}$ genes expression in airway smooth muscle cells and promote their proliferation by increased extracellular matrix proteins production in asthma. BMC Pulm Med. 2016;16:94.

20. Katz LE, Gleich GJ, Hartley BF, Yancey SW, Ortega HG. Blood eosinophil count is a useful biomarker to identify patients with severe eosinophilic asthma. Ann Am Thorac Soc. 2014;11(4):531-6.

21. Mehta AA, Mahajan S. Role of cytokines in pathophysiology of asthma. IJPT. 2006:5(1):1-0. Available at: http://www.bioline.org.br/pdf?pt06001.

22. Johansson MW. Activation states of blood eosinophils in asthma. Clin Exp Allergy. 2014;44(4):482-98.

23. Gregory B, Kirchem A, Phipps S, Gevaert P, Pridgeon C, Rankin SM, et al. Differential regulation of human eosinophil IL-3, IL-5, and GM-CSF receptor a-chain expression by cytokines: IL-3, IL-5, and GM-CSF down-regulate IL-5 receptor a expression with loss of IL-5 responsiveness, but up-regulate IL-3 receptor a expression. J Immunol. 2003;170(11):5359-66.

24. Yoshimura-Uchiyama C, Yamaguchi M, Nagase H, Matsushima K, Igarashi T, Iwata T, et al. Changing expression of IL-3 and IL-5 receptors in cultured human eosinophils. Biochem Biophys Res Commun. 2003;309(1):26-31.

25. Tavernier J, Tuypens T, Plaetinck G, Verhee A, Fiers W, Devos R. Molecular basis of the membrane-anchored and two soluble isoforms of the human interleukin 5 receptor alpha subunit. Proc Natl Acad Sci U S A. 1992;89(15): 7041-5.

26. Liu LY, Sedgwick JB, Bates ME, Vrtis RF, Gern JE, Kita H, et al. Decreased expression of membrane IL-5 receptor alpha on human eosinophils: II. IL-5 down-modulates its receptor via a proteinase-mediated process. J Immunol. 2002:169(11):6459-66.

27. Wilson TM, Maric I, Shukla J, Brown M, Santos C, Simakova O, et al. Interleukin-5 receptor a levels in patients with marked eosinophilia or mastocytosis. J Allergy Clin Immunol. 2011;128(5):1086-92.

28. Selvaraja M, Abdullah M, Shah AMd, Arip MB, Amin Nordin S. Role of cytokine il-5 and il-25 as biomarkers in systemic lupus erythematosus. Lupus Science \& Medicine 2017:4.

29. Wu Z, Zhong J, Su C, Huang Y, Huang T, Xu Z. Eosinophilia triggers changes in IL-5, eotaxin and IL-17, and acts as a prognostic biomarker for atopic dermatitis. Trop J Pharm Res. 2017;16(5):1167-72. Available at: https://www. ajol.info/index.php/tjpr/article/view/157035.

30. Rosenberg HF, Dyer KD, Foster PS. Eosinophils: changing perspectives in health and disease. Nat Rev Immunol. 2013;13(1):9.

31. Hogan SP, Rosenberg HF, Mogbel R, Phipps S, Foster PS, Lacy P, et al. Eosinophils: biological properties and role in health and disease. Clin Exp Allergy. 2008;38(5):709-50

32. Ramos-Barbón D, Fraga-Iriso R, Brienza NS, Montero-Martínez C, VereaHernando $\mathrm{H}$, Olivenstein $\mathrm{R}$, et al. T cells localize with proliferating smooth muscle a-actin+ cell compartments in asthma. Am J Respir Crit Care Med. 2010;182(3):317-24.

33. Wegner CD, Gundel RH, Reilly P, Haynes N, Letts LG, Rothlein R. Intercellular adhesion molecule-1 (ICAM-1) in the pathogenesis of asthma. Science. 1990; 247(4941):456-9.

34. Banerjee ER, Jiang Y, Henderson WR Jr, Scott LM, Papayannopoulou T. a4 and $\beta 2$ integrins have nonredundant roles for asthma development, but for optimal allergen sensitization only a4 is critical. Exp Hematol. 2007;35(4):605-17.

35. Johansson MW, Annis DS, Mosher DF. Alpha(M)beta (2) integrin-mediated adhesion and motility of IL-5-stimulated eosinophils on periostin. Am J Respir Cell Mol Biol. 2013;48(4):503-10.

36. Li W, Gao P, Zhi Y, Xu W, Wu Y, Yin J, et al. Periostin: its role in asthma and its potential as a diagnostic or therapeutic target. Respir Res. 2015;16(1):57.

37. Tartibi HM, Bahna SL. Clinical and biological markers of asthma control. Expert Rev Clin Immunol. 2014;10(11):1453-61.

38. Trejo Bittar HE, Yousem SA, Wenzel SE. Pathobiology of severe asthma. Annu Rev Pathol. 2015:10:511-45.

39. Szefler SJ, Wenzel S, Brown R, Erzurum SC, Fahy JV, Hamilton RG, et al. Asthma outcomes: biomarkers. J Allergy Clin Immunol. 2012;129(3):S9-S23.

40. Corren J, Lemanske RF Jr, Hanania NA, Korenblat PE, Parsey MV, Arron JR, et al. Lebrikizumab treatment in adults with asthma. N Engl J Med. 2011;365(12):1088-98.

41. Kim M-A, Shin YS, Pham LD, Park H-S. Adult asthma biomarkers. Curr Opin Allergy Clin Immunol. 2014;14(1):49-54.

42. Berry M, Shaw D, Green R, Brightling C, Wardlaw A, Pavord I. The use of exhaled nitric oxide concentration to identify eosinophilic airway inflammation: an observational study in adults with asthma. Clin Exp Allergy. 2005;35(9):1175-9.

43. Scichilone N, Battaglia S, Taormina S, Modica V, Pozzecco E, Bellia V. Alveolar nitric oxide and asthma control in mild untreated asthma. J Allergy Clin Immunol. 2013;131(6):1513-7.

44. Haldar P, Brightling CE, Hargadon B, Gupta S, Monteiro W, Sousa A, et al. Mepolizumab and exacerbations of refractory eosinophilic asthma. N Engl J Med. 2009;360(10):973-84.

45. Calhoun WJ, Ameredes BT, King TS, Icitovic N, Bleecker ER, Castro M, et al. Comparison of physician-, biomarker-, and symptom-based strategies for adjustment of inhaled corticosteroid therapy in adults with asthma: the BASALT randomized controlled trial. Jama. 2012;308(10):987-97.

46. Wu D, Zhou J, Bi H, Li L, Gao W, Huang M, et al. CCL11 as a potential diagnostic marker for asthma? J Asthma. 2014;51(8):847-54.

47. Machura E, Rusek-Zychma M, Jachimowicz M, Wrzask M, Mazur B, KasperskaZajac A. Serum TARC and CTACK concentrations in children with atopic 
dermatitis, allergic asthma, and urticaria. Pediatr Allergy Immunol. 2012; 23(3):278-84.

48. Nguyen CTH, Kambe N, Ueda-Hayakawa I, Kishimoto I, Ly NTM, Mizuno K, et al. TARC expression in the circulation and cutaneous granulomas correlates with disease severity and indicates Th2-mediated progression in patients with sarcoidosis. Allergol Int. 2018 Oct; 67(4):487-95.

49. Wadsworth S, Sin D, Dorscheid D. Clinical update on the use of biomarkers of airway inflammation in the management of asthma. J Asthma Allergy. 2011;:777.

50. Castro M, Corren J, Pavord ID, Maspero J, Wenzel S, Rabe KF, et al. Dupilumab efficacy and safety in moderate-to-severe uncontrolled asthma. N Engl J Med. 2018;378(26):2486-96.

51. Mathur SK, Schwantes EA, Jarjour NN, Busse WW. Age-related changes in eosinophil function in human subjects. Chest 2008; 133(2): 412-419.

52. Maier T, Güell M, Serrano L. Correlation of mRNA and protein in complex biological samples. FEBS Lett. 2009;583(24):3966-73.

\section{Publisher's Note}

Springer Nature remains neutral with regard to jurisdictional claims in published maps and institutional affiliations.

Ready to submit your research? Choose BMC and benefit from:

- fast, convenient online submission

- thorough peer review by experienced researchers in your field

- rapid publication on acceptance

- support for research data, including large and complex data types

- gold Open Access which fosters wider collaboration and increased citations

- maximum visibility for your research: over $100 \mathrm{M}$ website views per year

At BMC, research is always in progress.

Learn more biomedcentral.com/submissions 